\title{
A EMERGÊNCIA DOS MERCADOS INSTITUCIONAIS NO ESPAÇO RURAL BRASILEIRO: AGRICULTURA FAMILIAR E SEGURANÇA ALIMENTAR E NUTRICIONAL
}

\section{EMERGENCE OF INSTITUTIONAL MARKETS IN BRAZILIAN RURAL AREAS: FAMILY FARMING AND FOOD AND NUTRITIONAL SAFETY}

\author{
Raphael Fernando Diniz ${ }^{1}$, Carlos de Castro Neves Neto ${ }^{1}$, Antonio Nivaldo Hespanhol ${ }^{1}$ \\ ${ }^{1}$ Universidade Estadual Paulista "Júlio de Mesquita Filho"(UNESP), São Paulo, SP, Brasil
}

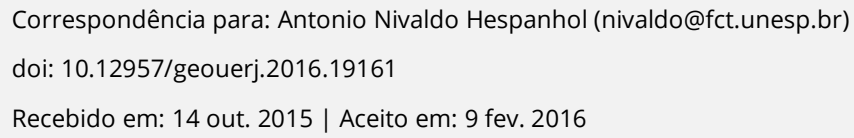

\section{RESUMO}

No presente artigo serão analisadas as principais contribuições que a criação de mercados institucionais tem gerado aos agricultores familiares brasileiros e, em contraponto, apresentar os obstáculos que lhes impedem o acesso ou a permanência nestes mercados. Para tanto, foram realizadas leituras de obras que tratam do tema, além de terem sido feitas entrevistas com diferentes agentes sociais responsáveis pela operacionalização de programas como o PAA, PNAE e o Programa Paulista da Agricultura de Interesse Social (PPAIS) no município de Dracena, no oeste do Estado de São Paulo. Das análises realizadas, concluiu-se que tais programas têm grande potencial para engendrar ações de desenvolvimento rural sustentável no campo brasileiro e garantir a segurança alimentar e nutricional de populações carentes. Para tanto, é necessário que o poder público adote medidas que visem dirimir ou pelo menos amenizar os problemas que limitam o acesso e/ou permanência dos agricultores familiares aos programas direcionados à agricultura familiar.

Palavras-chave: Mercados Institucionais; PAA; PNAE; Agricultura Familiar; Segurança Alimentar e Nutricional.

\section{ABSTRACT}

The present paper analyzes the chief contributions from institutional markets generated to Brazilian family farmers and, by contrast, presents the obstacles that hinder their access or permanence in these markets. For such, readings were made of works that address the theme, and interviews were performed with different social agents responsible for the operationalization of programs like PAA, PNAE and São Paulo Program for Social Interest Farming (PPAIS) in Dracena municipality, in São Paulo state west region. Based on analyses made, it was concluded that such programs have great potential to yield sustainable rural development actions in Brazilian countryside and ensure food and nutritional safety of needy populations. For such, public authorities should adopt measures to minimize issues that limit family famers' access to and/or permanence in programs oriented to family farming.

Keywords: Institutional markets; PAA; PNAE; Family farming; Food and nutritional safety.

\section{INTRODUÇÃO}

O reconhecimento conferido pelo Estado brasileiro à agricultura familiar, a partir da década de 1990, e de forma mais significativa no início dos anos 2000, se expressou notoriamente através da criação de políticas públicas diferenciadas para este grupo social, que até esta década não havia sido objeto de ações específicas por parte do poder público. Para isso, contribuíram a pressão dos movimentos sociais 
- como o Grito da Terra Brasil, 1994 - e a emergência de estudos realizados no país e no exterior que indicavam a permanência e a importância econômica e social dos agricultores familiares nos países desenvolvidos e em desenvolvimento (GRISA; SCHNEIDER, 2015).

A criação do Programa Nacional de Fortalecimento da Agricultura Familiar (PRONAF), em 1995, e sua institucionalização, em 1996, representou a primeira iniciativa realizada neste sentido, suscitando a emergência anos mais tarde de outras ações voltadas ao fortalecimento da agricultura familiar e a redução de sua vulnerabilidade social e econômica, destacando-se: a criação do Ministério do Desenvolvimento Agrário (MDA), em 1999, e da Secretaria da Agricultura Familiar no âmbito do MDA, no ano de 2001; a criação do Programa Garantia Safra, em 2002; do Seguro da Agricultura Familiar (SEAF), em 2004 e do Programa de Garantia de Preços da Agricultura Familiar (PGPAF), em 2006; a elaboração do Plano Safra da Agricultura Familiar, a partir de 2003-2004; a elaboração da Política Nacional de Assistência Técnica e Extensão Rural (PNATER) para a agricultura familiar e reforma agrária, em 2004; a instituição da Lei nº 11.326, denominada Lei da Agricultura Familiar, no ano de 2006.

Concomitantemente a essas ações, foram elaboradas políticas públicas pautadas na criação de mercados institucionais para a agricultura familiar e voltadas para a segurança alimentar e nutricional de populações em situação de risco e vulnerabilidade social, como o Programa de Aquisição de Alimentos (PAA), criado em 2003, e o Programa Nacional de Alimentação Escolar (PNAE), existente desde a década de 1950 , mas que a partir de 2009, através da Lei ํㅜำ 11.947 , passou a exigir que pelo menos $30 \%$ dos recursos repassados aos municípios pelo Fundo Nacional de Desenvolvimento da Educação (FNDE) passassem a ser alocados na aquisição direta de gêneros alimentícios de agricultores familiares e suas organizações, por intermédio de chamadas públicas. Ademais, a partir de 2012, os mercados para os produtos da agricultura familiar foram novamente ampliados com a criação de mais uma modalidade do PAA, denominada Compra Institucional, a qual permite às instituições federais, estaduais e municipais adquirir alimentos de produtores familiares através de chamadas públicas, as quais têm um nível de exigência bem inferior do que os processos licitatórios previstos na Lei 8.666, instituída no ano de 1993. 
De acordo com Grisa e Schneider (2015), programas como o PAA e o PNAE têm estimulado os governos estaduais e municipais a criarem seus próprios mecanismos de compras públicas, além de contribuir para a valorização da produção local/regional, ecológica/orgânica e promover ações de justiça social, equidade e qualificação dos produtos da agricultura familiar. Porto et al. (2013) destacam que, em virtude da crescente diversificação dos produtos adquiridos pelo PAA, incluindo a aquisição de sementes crioulas para distribuição aos agricultores e a compra de produtos orgânicos, o programa tem tido contribuição importante para a promoção da agrobiodiversidade, fomentando a produção de alimentos ligados às culturas locais/regionais e cultivados com a adoção de práticas sustentáveis, como as técnicas agroecológicas, colaborando, destarte, para uma alimentação saudável e adequada. Além disso, sob uma perspectiva das relações de gênero no campo, Siliprandi e Cintrão (2011) ressaltam o potencial do PAA na valorização do trabalho das mulheres na agricultura, fortalecendo a sua autonomia pessoal e econômica, bem como aumentando os laços de sociabilidade e incrementando autoestima.

Apesar dos avanços alcançados ao longo das duas últimas décadas, os agricultores familiares ainda têm encontrado dificuldades para se manterem ou mesmo se inserirem nestes programas, enfrentando restrições como a falta de conhecimento sobre os mesmos, a burocracia de acesso, as dificuldades em se ajustar às normas sanitárias e à classificação de produtos etc. (GRISA; PORTO, 2015).

Diante desse contexto, busca-se analisar, neste artigo, as principais contribuições dos mercados institucionais para os agricultores familiares brasileiros e, em contraponto, apresentar os obstáculos que lhes impedem o acesso ou a permanência nestes mercados.

Para tanto, foram realizadas leituras de obras que tratam do tema, além de terem sido feitas entrevistas com diferentes agentes sociais responsáveis pela operacionalização de programas como o PAA, PNAE e o Programa Paulista da Agricultura de Interesse Social (PPAIS) no município de Dracena, no oeste do Estado de São Paulo. Foram entrevistadas as presidentes das associações de agricultores familiares e sem-terra do município e técnicos vinculados à Coordenadoria de Assistência Técnica Integral (CATI-SP). 
O texto está estruturado em duas partes, além da introdução e das considerações finais. Na primeira apresentamos os efeitos gerados à agricultura familiar pela criação dos mercados institucionais, fundamentando-nos tanto em leituras como em observações realizadas em campo. Na segunda parte discutimos os principais entraves que impossibilitam um melhor funcionamento dos mercados institucionais no país e no município de Dracena-SP.

\section{MERCADOS INSTITUCIONAIS E SUAS CONTRIBUIÇÕES PARA A EMANCIPAÇÃO SOCIAL DOS AGRICULTORES FAMILIARES E PARA A SEGURANÇA ALIMENTAR E NUTRICIONAL DE POPULAÇÕES EM SITUAÇÃO DE RISCO E VULNERABILIDADE SOCIAL}

A institucionalização de mercados institucionais, por meio de programas federais como o PAA e o PNAE tem implicado em uma série de externalidades positivas aos agricultores familiares, bem como às populações que são beneficiadas pela doação dos alimentos, no caso do PAA, e ampliado a qualidade da merenda escolar, no caso do PNAE.

Delgado et al. (2005) destacam que um dos efeitos gerados pelo PAA nos locais de abrangência dos polos de compra da Companhia Nacional de Abastecimento (CONAB) e em outros onde as compras institucionais foram feitas através de convênios firmados entre o Ministério do Desenvolvimento Social (MDS), as municipalidades e os estados da federação, foi a recuperação dos preços pagos aos agricultores pelos seus produtos nos mercados locais e regionais. Muitas vezes, de acordo com os autores, o simples anúncio da compra pública de determinado produto já foi suficiente para elevar o seu preço no mercado, como ocorreu, por exemplo, nas compras de rapadura realizadas pelo governo do Piauí, de milho, feijão e arroz nos três polos de compra do estado de Rondônia (2003) e de milho e feijão em Teodoro Sampaio-SP (2003). Dessa forma, o PAA vem contribuindo para a elevação dos preços pagos aos produtores e, também, diminuindo a ação dos atravessadores que normalmente pagam um preço bem inferior aos alimentos produzidos pelos agricultores familiares.

Além de possibilitar a venda dos produtos dos agricultores familiares no mercado a preços mais remuneradores, o PAA tem contribuído para ampliar o nível de organização e de planejamento da 
oferta, uma vez que a compra de alimentos não desobriga os agricultores do cumprimento de regras de classificação, acondicionamento, atendimento das exigências sanitárias e de higiene inerentes à comercialização dos produtos (DELGADO et al., 2005). Neste sentido, Grisa (2009) destaca que 0 programa tem estimulado melhorias nos processos de acondicionamento, conservação e higiene dos alimentos, bem como a adoção de práticas mais sustentáveis de cultivo e de agregação de valor.

Ademais, o PAA tem estimulado o aumento, a diversificação e a melhoria da qualidade da produção para o autoconsumo e viabilizado uma melhor estruturação dos produtores para que consigam comercializar os seus produtos nas praças em que não há produção apoiada pelo programa (DELGADO et al., 2005). Zimmermann e Ferreira (2008) ressaltam que o PAA fomentou mudanças na matriz produtiva dos estabelecimentos de agricultores familiares participantes do programa no município de Mirandiba-PE, uma vez que grande parte deles passou a introduzir legumes, verduras e frutíferas no rol de alimentos cultivados, o que contribuiu para a revalorização das culturas agrícolas locais, diversificação e melhoria dos hábitos alimentares de suas famílias. Ou seja, o PAA, além de propiciar o aumento e a diversificação da produção de alimentos nos estabelecimentos rurais familiares, tem contribuído para a melhoria nutricional dos próprios agricultores e suas famílias.

No que tange aos efeitos gerados às populações que se beneficiam da doação dos alimentos, Delgado et al. (2005) apontam que o PAA tem fomentado a diversificação e o enriquecimento da alimentação servida nas escolas, creches, albergues, instituições de caridade, hospitais etc., o que contribui para a segurança alimentar e nutricional dos beneficiários e, como constataram Zimmermann e Ferreira (2008), para o aumento da frequência e do desempenho escolar dos estudantes, redução da evasão escolar e, especialmente, para a diminuição das doenças entre as crianças. Ainda no que diz respeito à melhoria da alimentação da população beneficiária do programa, torna-se oportuno fazer referência ao estudo de Romeiro d'Ávila e Silva (2011), por meio do qual foi verificado que os indivíduos atendidos nos hospitais, asilos e escolas dos municípios mineiros de Bocaiúva, São Francisco e Brasília de Minas apresentaram evoluções significativas em seu estado de saúde e educação, reduzindo o número de enfermos e melhorando os índices de aprendizagem escolar das crianças e adolescentes. 
Por outro lado, Pandolfo (2008) considera que o PAA tem se constituído num programa dinamizador das economias locais e de fomento à revitalização de tradicionais técnicas de beneficiamento da produção agrícola, como os históricos moinhos coloniais de processamento de milho e trigo no município de Tenente Portela, no Estado do Rio Grande do Sul. De acordo com o autor, a implementação do PAA estimulou a integração de várias instituições e organizações sociais e públicas com o intuito de elaborar propostas de desenvolvimento rural com o objetivo de atender os interesses do conjunto da sociedade.

Considerando o PAA enquanto uma política de desenvolvimento local, Grisa (2009) argumenta que o programa contribui para o fortalecimento dos capitais natural, cultural e social da agricultura familiar ao estimular a diversificação produtiva nos estabelecimentos rurais, promover a autonomia dos agricultores, criar uma ampla rede de atores da sociedade civil e de entidades públicas e incentivar o resgate e a preservação de costumes, hábitos e do saber-fazer das populações regionais, o que tem gerado um efeito catalisador do processo de empoderamento dos atores locais.

Em virtude dos alimentos serem produzidos e consumidos em locais relativamente próximos, o PAA tem fomentado a criação de circuitos curtos de comercialização, em contraponto aos circuitos longos e à desconexão entre produção e consumo, o que favorece a aproximação entre produtores e consumidores, a construção e o resgate de identidades, a valorização da cultura alimentar local/regional e do trabalho dos agricultores familiares, promovendo uma relação virtuosa de empoderamento deste grupo social e fortalecimento da segurança alimentar e nutricional de populações em situação de risco/vulnerabilidade social (GRISA; PORTO, 2015).

Cabe destacar, também, que no âmbito das relações de gênero no campo as modalidades Compra Direta da Agricultura Familiar (CDAF) e Compra da Agricultura Familiar para Doação Simultânea do PAA, por permitirem a comercialização de uma maior diversidade de alimentos, têm propiciado a criação de um importante mercado institucional para produtos tradicionalmente vinculados ao trabalho feminino, cultivados em áreas próximas às residências ou em áreas não aproveitadas para o cultivo de culturas agrícolas "comerciais", consideradas sob o ponto de vista da divisão do trabalho na 
agricultura familiar como de "responsabilidade dos homens" (SILIPRANDI; CINTRÃO, 2011). O programa também cria uma oportunidade comercial importante para os produtos processados, permitindo agregar valor à produção da agricultura familiar, e para um conjunto diverso de produtos do extrativismo, os quais são considerados, em grande parte, como "atribuições das mulheres" nos estabelecimentos de agricultura familiar (SILIPRANDI; CINTRÃO, 2011). O protagonismo feminino na condução do programa está também associado à maior atenção que as mulheres têm com a qualidade e a conservação dos alimentos, o que se reflete tanto no âmbito do cuidado com os processos de acondicionamento e/ou beneficiamento quanto na busca da redução/eliminação do uso de agrotóxicos nos manejos agrícolas (SILIPRANDI; CINTRÃO, 2011).

Com relação ao PNAE, estudos recentes desenvolvidos por Peixinho (2013), Sambuichi et al. (2014) e Triches (2015) destacam a contribuição do programa para a segurança alimentar e nutricional dos escolares e para a geração de renda complementar aos agricultores familiares. Dentre as principais externalidades positivas geradas pelo programa, destacam-se: a capacidade de promover hábitos alimentares mais saudáveis, tendo em vista a obrigatoriedade da oferta de frutas e hortaliças, a proibição de bebidas de baixo valor nutricional (refrigerantes e refrescos em pó) e a restrição a alimentos com alta quantidade de gordura, sal e açúcar (PEIXINHO, 2013); o fomento à produção orgânica e/ou agroecológica (PEIXINHO, 2013); o estímulo a uma maior aproximação entre comunidade, nutricionistas, produtores familiares, Conselho de Alimentação Escolar (CAE) e entidades de assistência técnica e extensão rural (ATER) (SAMBUICHI et al., 2014); a ampliação do debate nas instituições de ensino superior sobre o tema da alimentação escolar, tem fomentado a criação de novos conteúdos nos cursos de nutrição com o intuito de possibilitar a superação dos desafios criados pela nova forma de trabalhar a alimentação nas escolas (SAMBUICHI et al., 2014); o incentivo ao cooperativismo e à constituição de organizações formais de agricultores, o que contribui para um maior poder de barganha na compra de insumos, no processamento e na aquisição de embalagem dos alimentos de alta perecibilidade e redução nos custos de transporte (TRICHES, 2015).

Percebe-se, por meio desses estudos, o potencial do PAA e do PNAE no fortalecimento dos circuitos curtos de comercialização, na complementação da renda dos agricultores familiares, na melhoria da sua 
qualidade de vida e dos hábitos alimentares nas cidades, fomentando padrões sustentáveis de produção e consumo.

No caso da pesquisa de campo realizada no município de Dracena, constatamos que dos 16 municípios pertencentes à região atendida pelos serviços de Assistência Técnica e Extensão Rural - ATER do Escritório de Desenvolvimento Rural (EDR) da CATI, o PAA está sendo executado em dez, envolvendo dezoito associações de agricultores familiares (58\% do total de associações da região), com a participação de 900 agricultores familiares e o atendimento de 200 entidades públicas. O PNAE, por sua parte, está sendo executado em todos os municípios da região de Dracena, os quais têm destinado de $10 \%$ a $60 \%$ do total dos recursos repassados pelo Fundo Nacional de Desenvolvimento da Educação (FNDE) em compras de produtos da agricultura familiar. Ou seja, em alguns municípios a Lei № 11.947/09 não está sendo cumprida pelo poder público, tendo em vista que os repasses para a compra de produtos da agricultura familiar são inferiores a 30\% do total recebido do FNDE. De acordo com os técnicos da CATI, a instituição não tem obtido acesso fácil aos valores gastos pelas prefeituras com o PNAE, o que dificulta o controle de quanto e como têm sido gastos os recursos do fundo. Ainda de acordo com os técnicos da CATI, do total de agricultores participantes do PNAE, 90\% estão cadastrados no PAA, obtendo uma importante renda extra para a reprodução familiar e manutenção dos membros da família no campo.

No município de Dracena, a Associação dos Produtores Rurais de Dracena (APRD) tem sido responsável pelo recebimento dos produtos dos associados e entrega às entidades recebedoras: escolas, hospitais, penitenciárias, asilos etc. Para a realização deste serviço, a APRD cobra $10 \%$ do valor total do financiamento do programa em que foi aprovado o projeto, recursos que são utilizados para pagar o salário dos funcionários, o transporte dos alimentos e outros custos de funcionamento da Associação, de acordo com as informações fornecidas pela presidente da associação, por meio de entrevista.

Com relação à participação dos associados nos programas institucionais de aquisição de alimentos, 80 fazem parte de projetos do PAA e 30 entregam produtos ao PNAE, fornecendo alimentos para o município de Dracena, Panorama, Paulicéia, Irapuru e Nova Guataporanga. De acordo com a 
presidente da APRD, a menor quantidade de agricultores no PNAE em relação ao PAA se justifica pela maior exigência deste programa em termos de regularidade na entrega dos alimentos nas escolas, demandando um compromisso maior do que o exigido pelo PAA.

No que tange à renda obtida pelos agricultores, esta pode variar de $\mathrm{R} \$ 8$ mil anuais, quando participa apenas do PAA, a $\mathrm{R} \$ 50$ mil anuais, se o agricultor participar também do PNAE e do Programa Paulista de Agricultura de Interesse Social (PPAIS), do governo estadual.

Geralmente os preços pagos pelos alimentos se situam dentro dos valores do mercado ou até um pouco acima.

Já no caso dos agricultores sem-terra reunidos em torno da Associação J. Marques dos Trabalhadores Rurais de Jaciporã, acampados há 16 anos no município de Dracena, foi possível constatar, por meio de entrevista com a presidente da associação, que atualmente a entidade fornece alimentos ao PAA e PNAE, sendo que 14 associados fornecem alimentos ao PNAE e 65 ao PAA. A produção de alimentos é realizada em terras arrendadas pelas famílias sem-terra, nas quais são produzidas hortaliças e outras culturas agrícolas por meio de manejos ecológicos, como o uso de insumos naturais de combate às doenças e pragas e fertilizantes orgânicos para adubação do solo.

O trabalho nas áreas de cultivo é realizado de forma coletiva, dividido em grupos de 20 pessoas, as quais realizam os serviços somente pelas manhãs e, à tarde, desenvolvem outras atividades nos terrenos em que estão acampadas. Após a comercialização dos alimentos, os recursos recebidos são divididos igualmente entre todos os membros dos grupos.

De acordo com a presidente da Associação J. Marques, os resultados obtidos com a participação nestes programas governamentais têm feito com que os filhos possam acreditar que é possível residir e trabalhar no campo com geração de renda e qualidade de vida. A este respeito, ela ressalta que existem hoje pessoas que trabalhavam na zona urbana de Dracena e de outros municípios e estão retornando ao 
campo em busca de melhores condições de vida e trabalho, graças aos resultados gerados pelo PAA e PNAE.

Destaca-se, ademais, o papel desempenhado pelos técnicos vinculado à CATI para o crescimento e consolidação da associação, especialmente na orientação dos membros da associação para que possam ter acesso às políticas públicas direcionadas aos agricultores familiares.

Observa-se, portanto, que o PAA e o PNAE têm se constituído em importantes programas de complementação de renda para os agricultores familiares e sem-terra de Dracena, estimulando à organização social, a participação política e incentivando o retorno dessa população ao campo. Esses indivíduos, que foram forçados pelas circunstâncias a deixarem o campo, atualmente sobrevivem da produção de alimentos nos espaços rurais.

Não obstante, os efeitos positivos sobre a economia familiar e sobre as relações sociopolíticas dos agricultores familiares e sem-terra de Dracena, esses sujeitos ainda têm enfrentado dificuldades para participar destes programas ou se manter neles, em virtude de questões burocráticas relativas à entrega dos produtos e prestação de contas, da falta de informações sobre a existência dos programas ou datas limites para cadastramento nos mesmos. A própria CATI também enfrenta dificuldades decorrentes do número reduzido de técnicos extensionistas para a prestação de serviços de qualidade e de forma continuada aos agricultores.

No tópico a seguir abordaremos, de forma mais aprofundada, esta questão a partir da leitura de textos que discutem os obstáculos que impedem os agricultores familiares brasileiros de terem acesso e/ou de permanecerem participando dos programas de compra institucionais de alimentos.

\section{OS LIMITES OPERACIONAIS DOS MERCADOS INSTITUCIONAIS E A NECESSIDADE DE APERFEIÇOAMENTOS}


Os limites e desafios enfrentados pelos agricultores familiares, por suas entidades representativas e pelas organizações públicas que prestam serviços essenciais à gestão e execução de programas como 0 PAA e o PNAE são de natureza múltipla e complexa, conformando distintas escalas (local, regional, nacional) e dimensões (econômica, social, política, educacional, gênero etc.) que impedem o funcionamento pleno, democrático, integrador e sustentável destes programas.

No caso do PAA, primeiramente cabe apontar que, apesar de ter havido o crescimento contínuo de seus recursos orçamentários e do número de agricultores envolvidos, esta expansão tem ocorrido num ritmo muito lento frente às demandas da agricultura familiar e de entidades públicas vinculadas à segurança alimentar e nutricional, como o Conselho Nacional de Segurança Alimentar e Nutricional (CONSEA) (GRISA; PORTO, 2015). Considerando as demandas levantadas pela sociedade civil organizada, percebe-se que o programa é ainda relativamente modesto em termos de recursos financeiros aplicados, do potencial que têm de crescimento e dos problemas alimentares que ainda persistem no campo e nas cidades (GRISA; PORTO, 2015).

Não bastasse o orçamento limitado, Sambuichi et al. (2014) também apontam que o atraso e a descontinuidade na liberação dos recursos têm se constituído no principal problema enfrentado pelos agricultores familiares participantes do PAA, como descrito em diversos estudos consultados pelos autores e nas entrevistas realizadas com agentes públicos responsáveis pela sua execução. As razões para a ocorrência dos atrasos são diversas, mas geralmente estão associadas às elevadas exigências burocráticas do programa e às dificuldades inerentes ao seu sistema operacional (SAMBUICHI et al., 2014).

Por parte dos agricultores familiares, os entraves enfrentados para participação no PAA se iniciam, muitas vezes, já na obtenção da Declaração de Aptidão ao PRONAF (DAP), documento ainda muito difícil de ser conseguido em diversos municípios do país e para distintos grupos sociais, como os extrativistas e povos tradicionais (SAMBUICHI et al., 2014). 
A situação crítica vivenciada por várias entidades de ATER pública do país em relação à carência de profissionais para prestação de serviços aos agricultores familiares é outro fator limitante, dentre os quais a emissão de DAPs. De acordo com a Associação Brasileira das Entidades Estaduais de Assistência Técnica e Extensão Rural (ASBRAER), as empresas públicas de ATER (EMATERs, EPAGRI, CATI, ITESP etc.) são responsáveis pela emissão de mais de $70 \%$ do total de 5,2 milhões de DAPs existentes no Brasil (ASBRAER, 2015).

Considerando que, em 2014, o total de extensionistas dessas entidades que prestam serviços diretamente em campo é de 15.745 profissionais (ASBRAER, 2014), e que existem no Brasil 4.366.267 estabelecimentos de agricultura familiar (IBGE, 2006), verifica-se uma média bastante elevada na relação de estabelecimentos de agricultura familiar/técnicos extensionistas no país, da ordem de 277 estabelecimentos por técnico, situação que se torna ainda mais crítica na região nordeste, onde há apenas um técnico para cada 437 estabelecimentos (Tabela 1). Se considerarmos que para a prestação de serviços de qualidade aos agricultores deve haver um técnico para cada 80 a 100 famílias, conforme indicado pelo MDA (CAPORAL, 2014), verificaremos que existe no país um déficit de 27.934 técnicos extensionistas, dos quais 60,4\% são referentes à quantidade necessária para atender apenas a carência da região nordeste, a mais pobre e com maior número de estabelecimentos de agricultura familiar de todas as regiões brasileiras.

\begin{tabular}{c|c|c|c|c}
\hline $\begin{array}{c}\text { País e } \\
\text { Regiões }\end{array}$ & $\begin{array}{c}\text { Número de } \\
\text { técnicos de campo }\end{array}$ & $\begin{array}{c}\text { Total de } \\
\text { estabelecimentos de } \\
\text { agricultura familiar }\end{array}$ & $\begin{array}{c}\text { Relação } \\
\text { Técnico/Estabelecimento } \\
\text { de agricultura familiar }\end{array}$ & $\begin{array}{c}\text { Déficit } \\
\text { de } \\
\text { técnicos }\end{array}$ \\
\hline Brasil & 15.745 & 4.366 .267 & $1: 277$ & 27.934 \\
Norte & 2.617 & 413.101 & $1: 158$ & 1.514 \\
Centro-Oeste & 1.318 & 217.531 & $1: 165$ & 857 \\
Sudeste & 3.456 & 699.978 & $1: 203$ & 3.544 \\
Sul & 3.353 & 849.997 & $1: 254$ & 5.147 \\
Nordeste & 5001 & 2.187 .295 & $1: 437$ & 16.871 \\
\hline
\end{tabular}


Tabela 1. Número de técnicos de campo, total de estabelecimentos de agricultura familiar, Relação técnico/estabelecimento de agricultura familiar e Déficit de técnicos em 2014, Brasil e Grandes Regiões. Fonte: Número de técnicos de campo (ASBRAER, 2014); Total de Estabelecimentos de Agricultura Familiar (IBGE, 2006).

Outra questão colocada como importante desafio político e institucional para uma melhor operacionalização do PAA é a dificuldade de articulação entre ministérios e demais órgãos da administração pública nas escalas nacional, estadual e municipal. Grisa e Porto (2015), a este respeito, destacam que nem sempre o poder público municipal/estadual tem sido parceiro na execução do programa e raramente existem entidades mediadoras que tomam a iniciativa de articulação política necessária a este fim. Com efeito, criam-se elementos que dificultam o acesso de um maior número de agricultores familiares ao PAA ou mesmo a continuidade daqueles que já são fornecedores de alimentos ao programa.

A descontinuidade dos projetos também tem gerado sérios problemas para os agricultores familiares, pois os obriga a buscar novos mercados temporários para sua produção, retornar aos mercados "tradicionais" dominados por "atravessadores" ou, de forma mais problemática, perder a produção pela carência de compradores ou pelos preços inviáveis pagos pelos produtos (GRISA; PORTO, 2015).

Por outro lado, a deficiente estrutura de transporte, estocagem e beneficiamento da produção agropecuária foi identificada por Sambuichi et al. (2014) como o segundo problema mais citado nos estudos produzidos sobre a execução do PAA no país. Grandes distâncias entre o centro de consumo e as unidades de produção, condições de trafegabilidade das estradas vicinais e carência de tecnologias de conservação dos produtos, como tanques de resfriamento de leite (no caso da modalidade Incentivo à Produção e Incentivo de Leite - PAA Leite), são consideradas questões que limitam o acesso dos agricultores familiares ao programa, sobretudo por parte dos menos capitalizados e com menor nível de organização social (cooperativas ou associações) (ibidem).

Complementarmente a estas questões, destacam-se: o baixo limite de compra por produtor e dificuldade de adequação à legislação sanitária (SAMBUICHI et al., 2014); crescente burocratização do 
programa, desconhecimento do sobre-preço e dos mecanismos de avaliação da conformidade orgânica (GRISA; PORTO, 2015); falta de controle social, carência de assistência técnica e pouca divulgação do programa (ZIMMERMANN; FERREIRA， 2008; ROMEIRO D'ÁVILA;; SILVA, 2011; SAMBUICHI et al., 2014); morosidade dos processos de análise e aprovação das propostas de participação no programa e de prestação de contas (ROMEIRO D’ÁVILA; SILVA, 2011); carência de planejamento para aplicação dos recursos, de acordo com as especificidades das safras, e falta de critérios claros para definir os territórios de atuação (ZIMMERMANN; FERREIRA, 2008); não obstante tenham expressiva participação direta nas atividades produtivas rurais, há ainda um baixo percentual de mulheres constando formalmente nos contratos de fornecimento do programa, o que cria fortes desafios a construção de uma maior autonomia econômica do público feminino no campo, reforça a invisibilidade de seu protagonismo enquanto agente econômico e produtivo na agricultura familiar e, consequentemente, perpetua sua condição de subalternidade ao homem "chefe de família" (SILIPRANDI; CINTRÃO, 2011).

Com relação ao PNAE, as compras feitas da agricultura familiar ainda são muito recentes em comparação ao PAA, o que, de acordo com Sambuichi et al. (2014), se reflete na carência de estudos e dados sistematizados que possibilitem uma análise mais ampla dos avanços e desafios do programa. Em que pese estas questões, os autores apontam que a principal dificuldade para a aplicação da Lei $n^{0}$ 11.947/09 é a incipiente e/ou deficiente estrutura organizativa dos produtores familiares, uma vez que implica, muitas vezes, na impossibilidade de emissão de notas fiscais de venda dos produtos e no despreparo para atender às exigências sanitárias e de regularidade de fornecimento. Percebe-se, com efeito, que mesmo com os avanços promovidos com a experiência do PAA, os agricultores familiares ainda não estão suficientemente organizados para fornecer alimentos ao PNAE na escala, regularidade e qualidade exigidas pelas escolas, fato que se torna ainda mais crítico quando os estabelecimentos de ensino ou as prefeituras não possuem centros de recebimento e armazenagem dos produtos agropecuários (SAMBUICHI et al., 2014).

Outras questões como: 1) dificuldade de logística; 2) baixos preços pagos para alguns produtos; 3) elevados custos de transportes e de embalagens de alimentos de alta perecibilidade; 4) burocratização 
dos mecanismos de acesso ao programa; 5) carência de documentação por parte dos agricultores familiares; 6) desconfiança destes sujeitos em relação ao poder público; 7) informalidade das agroindústrias; 8) falta de articulação entre produtores e gestores do programa; e, de forma muito perversa, 9) a atuação de movimentos políticos oposicionistas que fazem o uso de retóricas e ações divergentes com o intuito de enfraquecer o programa e manter seu status quo, são também apontadas como fatores restritivos a serem superados para que o PNAE possa possibilitar, de fato, um maior acesso e permanência dos agricultores familiares no mercado institucional criado pelo programa (TRICHES; SCHNEIDER, 2012; TRICHES; GRISA, 2015).

No caso da realidade observada em campo, no município de Dracena, uma das principais dificuldades enfrentadas pelos agricultores para participarem do PAA e do PNAE é o desconhecimento "do que produzir" e "como entregar" os produtos cultivados em seus estabelecimentos rurais, tendo em vista que muitos não sabem como fornecer os alimentos em quantidade, diversidade e qualidade demandada pelas entidades receptoras.

Este problema se torna ainda mais grave quando se leva em consideração a carência de técnicos extensionistas na CATI, visto que, segundo o diretor do Escritório de Desenvolvimento Rural de Dracena, a maioria dos municípios tem apenas um técnico trabalhando e a relação de "técnicos/agricultores" varia de 1 para 600 a 1 para 1.200 nos municípios da região, sendo que 0 último concurso público realizado para a contratação de extensionistas ocorreu no ano de 2006.

Dentre as outras dificuldades enfrentadas pelos agricultores familiares para fazer a gestão do PAA, destacam-se: carência de funcionários em suas associações e de infraestrutura adequada para operacionalizar o programa, realizar a prestação de contas na internet, prestar informações sobre as notas fiscais de venda dos produtores para as associações e destas para o PAA.

Com relação à Associação dos Produtores Rurais de Dracena, um dos principais problemas enfrentados atualmente, e que tem relação direta com a carência de técnicos agropecuários na CATI, é a demanda por um serviço de ATER exclusivo e contínuo aos seus associados. Até recentemente havia 
um engenheiro agrônomo prestando este tipo de serviço para a associação, pelo qual cobrava $R \$$ 100,00 por mês por agricultor para a realização de visitas mensais em seus estabelecimentos rurais. Porém, atualmente não há nenhum profissional assessorando os agricultores familiares associados, o que em determinados casos pode implicar na redução da produção e da produtividade dos alimentos cultivados para serem fornecidos aos programas.

Já no caso dos agricultores sem-terra da Associação J. Marques, o atraso no processo de reforma agrária obriga-os a ter que arrendar terras no município para a produção de alimentos, o que implica em gastos extras que reduzem os rendimentos obtidos com a venda destinada aos mercados institucionais que fazem parte.

Percebe-se, deste modo, que, não obstante os avanços alcançados ao longo dos últimos anos com leis e políticas criadas para fomentar, diversificar e fortalecer os mercados dos produtos da agricultura familiar, há ainda inúmeros desafios a serem superados para que os agricultores familiares possam, de fato, fazer da agricultura e pecuária atividades que possam lhes garantir a emancipação social e a segurança alimentar e nutricional de suas famílias e daquelas que se encontram em situação de risco e vulnerabilidade social nas cidades.

\section{CONSIDERAÇÕES FINAIS}

Mercados institucionais como o PAA e o PNAE têm demonstrado que a agricultura familiar passou a ser objeto de maior atenção do poder público no Brasil. Através dos mercados institucionais criados por tais programas tem se estimulado a diversificação produtiva no campo, a valorização da produção local/regional e agroecológica/orgânica, o uso de práticas mais sustentáveis de conservação dos recursos naturais, a melhoria da qualidade da produção para o autoconsumo, a dinamização dos mercados locais, a revitalização de tradicionais técnicas de beneficiamento da produção agrícola etc., contribuindo para a ampliação do empoderamento, a emancipação social dos produtores familiares e 0 desenvolvimento de suas comunidades e municípios. 
Por outro lado, no que diz respeito às populações beneficiadas pelos alimentos adquiridos através destes programas, percebe-se que tem ocorrido a diversificação e o enriquecimento da alimentação servida nas escolas, creches, albergues, instituições de caridade, hospitais etc., o que contribui para a segurança alimentar e nutricional dos beneficiários, para o aumento da frequência e do desempenho escolar dos estudantes, redução da evasão escolar e, especialmente, para a diminuição das doenças entre as crianças.

Não obstante os pontos positivos elencados neste estudo, percebe-se que ainda há muito a avançar para que tais programas cumpram plenamente seus propósitos, o que demanda a superação de limites e desafios de natureza múltipla e complexa, envolvendo distintas escalas (local, regional, nacional) e dimensões (econômica, social, política, educacional, gênero etc.), como buscamos demonstrar através da literatura que trata dos mercados institucionais e a partir de levantamento empírico realizado no município de Dracena.

Vislumbra-se, portanto, que tais programas têm grande potencial para engendrar ações de desenvolvimento rural sustentável no campo brasileiro e garantir a segurança alimentar e nutricional de populações carentes. Para tanto é necessário que o poder público adote medidas que visem dirimir ou pelo menos amenizar os problemas apontados, os quais têm limitado o acesso e a permanência dos agricultores familiares aos programas direcionados a agricultura familiar.

\section{AGRADECIMENTOS}

Agradecemos à Fundação de Amparo à Pesquisa do Estado de São Paulo (FAPESP) pela concessão da bolsa de Doutorado (Processo número: 2013/25725-8) e a Coordenação de Aperfeiçoamento de Pessoal de Nível Superior (CAPES) pela concessão de bolsa de pós - doutorado, pelo Programa Nacional de Pós - Doutorado (PNPD/CAPES), às presidentes das associações de agricultores familiares e sem-terra do município de Dracena e aos técnicos vinculados à Coordenadoria de Assistência Técnica Integral (CATI-SP) pelas entrevistas concedidas em campo. 


\section{REFERÊNCIAS}

ASBRAER - ASSOCIAÇÃO BRASILEIRA DE ASSISTÊNCIA TÉCNICA E EXTENSÃO RURAL. Assistência Téenica e Extensão Rural no Brasil: um debate nacional sobre as realidades e novos rumos para o desenvolvimento do país. Brasília: ASBRAER, 2014.

MDA e entidades de Ater se reúnem para aperfeiçoar parcerias voltadas para políticas de agricultura familiar. Disponível em: http://www.asbraer.org.br/noticias,mda-e-entidades-de-ater-se-reunem-paraaperfeicoar-parcerias-voltadas-para-politicas-de-agricultura-familiar,89269. Acesso em: 17 jul. 2015.

CAPORAL, F. R. Extensão rural como política pública: a difícil tarefa de avaliar. In: SAMBUICHI, R. H. R. et al. (Org.). Políticas agroambientais e sustentabilidade: desafios, oportunidades e lições aprendidas. Brasília: IPEA, 2014. p. 19-48

DELGADO, G. C.; CONCEIÇÃO, J. C. P. R. da; OLIVEIRA, J. J. de. Avaliação do programa de aquisição de alimentos da agricultura familiar - PAA. Brasília: Ipea, 2005. (Texto para Discussão, n. 1145).

GRISA, C. Desenvolvimento local, políticas públicas e meios de vida: uma análise do Programa de Aquisição de Alimentos (PAA). In: CONGRESSO DA SOCIEDADE BRASILEIRA DE ECONOMIA, ADMINISTRAÇÃO E SOCIOLOGIA RURAL (SOBER),47ํ․,2009, Porto Alegre. Anais... Porto Alegre: SOBER, 2009. p. 1-22. Disponível em: <http://www.sober.org.br/palestra/13/105.pdf> Acesso em: 29 jun. 2015

GRISA, C.; PORTO, S. I. As contribuições e os desafios para o desenvolvimento rural. In: GRISA, C.; SCHNEIDER, S. (Org.). Políticas públicas de desenvolvimento rural no Brasil. Porto Alegre: Editora da UFRGS, 2015. p. 155-180.

GRISA, C.; SCHNEIDER, S. Três gerações de políticas públicas para a agricultura familiar e formas de interação entre sociedade e Estado no Brasil. In: GRISA, C.; SCHNEIDER, S. (Org.). Políticas públicas de desenvolvimento rural no Brasil. Porto Alegre: Editora da UFRGS, 2015. p. 19-50.

INSTITUTO BRASILEIRO DE GEOGRAFIA E ESTATÍSTICA - IBGE. Censo Agropecuário 2006: Agricultura Familiar - Segunda apuração, Brasil, Grandes Regiões e Unidades da Federação. Rio de Janeiro: IBGE, 2006. Disponível em: $<$ http://www.sidra.ibge.gov.br/>. Acesso em 2 mar. 2015

PANDOLFO, M. C. O programa de aquisição de alimentos como instrumento revitalizador dos mercados regionais. Agriculturas, v. 5, n. 2, p.14-17, jun. 2008.

PEIXINHO, A. M. L. A trajetória do Programa Nacional de Alimentação Escolar no período de 2003-2010: relato do gestor nacional. Ciência \& Saúde Coletiva, v. 18, n. 4, p. 909-916, 2013.

PORTO, S. et al. Programa de Aquisição de Alimentos (PAA): dez anos de uma política pública múltipla e inovadora. In: DEL GROssi, M.; KROEFF, D. R. (Org.) PAA: 10 anos de aquisição de alimentos. Brasília, DF: MDS; Secretaria Nacional de Segurança Alimentar e Nutricional; Secretaria de Avaliação e Gestão da Informação, 2013. p. 35-47

ROMEIRO D'ÁVILA, C. A.; SILVA, S. P. Segurança Alimentar e Desenvolvimento Local: uma análise dos resultados do Programa de Aquisição de Alimentos (PAA) em Minas Gerais. Revista Políticas Públicas, São Luís, v. 15, n. 2, p. 335-346, jul./dez. 2011.

SAMBUICHI, R. H. S.et al. Compras Públicas Sustentáveis e Agricultura Familiar: a experiência do Programa de Aquisição de Alimentos (PAA) e do Programa Nacional de Alimentação Escolar (PNAE). In: SAMBUICHI, R. H. R. et al. (Org.).

Políticas agroambientais e sustentabilidade: desafios, oportunidades e lições aprendidas. Brasília: IPEA, 2014. p. 75-104.

SILIPRANDI, E.; CINTRÃO, R. As mulheres agricultoras no Programa de Aquisição de Alimentos (PAA). Segurança Alimentar e Nutricional, Campinas, v. 18, n. 2, p. 12-32, 2011. 
TRICHES, R. M. Repensando o mercado da alimentação escolar: novas institucionalidades para o desenvolvimento rural. In: GRISA, C.; SCHNEIDER, S. (Org.). Políticas públicas de desenvolvimento rural no Brasil. Porto Alegre: Editora da UFRGS, 2015. p. 181-200.

TRICHES, R. M.; GRISA, C. Entre mudanças e conservadorismos: uma análise dos programas de aquisição de alimentos (PAA e PNAE) a partir da retórica da intransigência. Revista NERA, Presidente Prudente-SP, v. 18, n. 26, p. 10-27, 2015.

TRICHES, R. M.; SCHNEIDER, S. Alimentação escolar e agricultura familiar: reconectando o consumo a produção. Saúde e Sociedade, São Paulo, v. 19, p. 933- 945, 2010.

ZIMMERMANN, S. A.; FERREIRA, A. P. El programa de adquisicion de alimentos de la agricultura familiar em MirandibaPE. In: SCOTTO, G. (Org.). Aun hay tiempo para el sol: pobrezas rurales y programas sociales. Brasil - Venezuela Guatemala Una mirada desde lo local. Rio de Janeiro: Actionaid, 2008. p. 28-64. 